\title{
DESIGN AND FABRICATION OF A MOBILE FUME EXTRACTOR
}

\author{
M. J. Omoregie ${ }^{1, *}$, T. I. F.-Akilaki ${ }^{2}$ and K. E. Kalu ${ }^{3}$

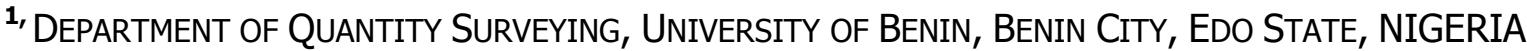 \\ 2, 3, Department of Production Engineering, University of Benin, Benin City, Edo State, Nigeria \\ E-mail addresses: ${ }^{1}$ monday.omoregie@uniben.edu, ${ }^{2}$ tina.odibi@uniben.edu, \\ 3 mastergoodnesskek@yahoo.com
}

\begin{abstract}
Welding processes produce fumes which are known to be dangerous to human health. In order for welders to work in a safe environment, a means of removing these fumes from the welding environment must be provided during the welding process. This is the purpose for which this paper has been developed. Fume extractors are generally known to be fixed to the walls of factories and places where fumes need to be extracted from. With the increase in welding needs outside the workshop environment, the need to have mobile fume extractors has become imperative. This need has been addressed in this paper. Materials for design and fabrication of the fume extractor were selected based on cost, safety, functionality, ease of availability and affordable maintainability. The fabricated fume extractor was tested on several welding sites and found to be very effective in extracting fumes from welders breathing zone. It was also observed that the function of the extractor did not adversely affect the welding process.
\end{abstract}

Keywords: fume extractor, outlet impeller, inlet impeller, radial velocity, fumes.

\section{INTRODUCTION}

Fumes and particles are released into the operator's breathing zone during welding operations, or when using flux with solders. These fumes can lead to occupational asthma and other allergic reactions when inhaled [1]. Intense testing by health institutes have shown that specialized equipment for extracting and filtering of dangerous fumes are necessary to prevent fumes from getting into the operators breathing zone [2].

Welding fumes consist of $99.5 \%$ particles and $0.5 \%$ of gases [3]. Particles in welding fumes that are a threat to human health are lead particles (in dust and smoke) larger than 0.1 micron and fumes of aliphatic aldehydes and isocyanides. The most common health challenges are short and irregular breathing, coughing, and tightness of the chest in combination with irritation of the eyes, headaches, dizziness and dry cracked skin [4].

The loss of productivity and working time due to employee illness is incalculable. An investment in a safe and productive working environment will protect employees and improve profitability. The aim of this work is to design and fabricate a portable fume extractor that is suitable for use in welding workshops and external welding sites.

The scope of this study is limited to the design and fabrication of a portable fume extractor that can extract fumes generated during welding processes in tropical regions. In the cause of carrying out this study, the following design considerations were given due attention; the machine should be efficient during use in the hot shop as well as easily movable (portability), safety and ease of operation. In addition, the cost of construction was also considered.

\section{METHODOLOGY}

\subsection{Materials used for Construction}

Engineering materials are materials whose properties are technologically useful. Selecting the right materials for a specific design is probably the single most important decision facing designers. 
Table 1: Table of Material Selection

\begin{tabular}{|c|c|c|c|c|}
\hline $\mathrm{S} / \mathrm{N}$ & $\begin{array}{l}\text { Machine } \\
\text { Component }\end{array}$ & Criteria for Selection & Material Selected & Reasons for Selection \\
\hline 1 & Frame & Formability and Weldability & Mild steel & $\begin{array}{l}\text { Low cost, good formability, } \\
\text { weldability and readily } \\
\text { available. }\end{array}$ \\
\hline 2 & Pan & $\begin{array}{l}\text { Weldability, durability and } \\
\text { formability }\end{array}$ & Mild steel & $\begin{array}{l}\text { Low cost, readily available and } \\
\text { can be easily welded. }\end{array}$ \\
\hline 3. & Hose & Flexibility and durability & Vulcanized rubber & $\begin{array}{l}\text { Easy movement from one point } \\
\text { to another without stress. }\end{array}$ \\
\hline 4. & Air Filter & Low cost and easy maintenance & Paper-based & $\begin{array}{l}\text { Ability to trap large amounts of } \\
\text { fumes from the welding zone. }\end{array}$ \\
\hline 5. & $\begin{array}{l}\text { Centrifugal } \\
\text { blower }\end{array}$ & $\begin{array}{l}\text { High Static pressure and suitability } \\
\text { for high temperature }\end{array}$ & $\begin{array}{l}\text { Radial bladed } \\
\text { centrifugal blower }\end{array}$ & $\begin{array}{l}\text { Ability to handle heavily } \\
\text { contaminated airstreams. }\end{array}$ \\
\hline 6. & Air duct & Flexibility and durability & Vulcanized rubber & $\begin{array}{l}\text { Effective and easy passage of } \\
\text { fumes. }\end{array}$ \\
\hline 7. & Storage tank & Strength, low cost and weldability & Mild steel & Ability to be rolled and welded \\
\hline 8. & Electric motor & $\begin{array}{l}\text { Ability to overcome shear stress, } \\
\text { durability, regulates speed and } \\
\text { torque }\end{array}$ & 1hp electric motor & $\begin{array}{l}\text { Regulates, speed, generates } \\
\text { torque. }\end{array}$ \\
\hline 9. & Rivet pins & High fatigue and impact strength & Stainless steel & Readily available \\
\hline 10. & Paint & $\begin{array}{l}\text { Corrosion resistance and good } \\
\text { texture }\end{array}$ & $\begin{array}{l}\text { Corrosion resistant } \\
\text { paint }\end{array}$ & $\begin{array}{l}\text { For good aesthetics, } \\
\text { preservative ability. }\end{array}$ \\
\hline
\end{tabular}

Materials are chosen for a variety of reasons such as cost effectiveness, availability and workability and affordability. Table 1 shows the various materials selected and reasons for their selection [5].

\subsection{Proposed Design}

The frame was fabricated by arranging angle bars in a cuboid, $506 \times 309 \times 309 \mathrm{~mm}$. The end of the angle bars were chamfered for proper lapping. Perpendicularity was ensured with the use of a trysquare and then it was joined by welding. A flat bar was used to partition the top part of the frame vertically to prevent vibration and ensure firmness. The mild steel pan was cut to the required dimension. A mild steel pan was rolled in a cylindrical form to a diameter of $55 \mathrm{~mm}$ on top of the frame to accommodate the capture hood which serves as inlet of fume into the machine. The air filter was inserted into the tank from the top pan and then locked from the top.

The centrifugal blower was installed on the left-hand side in the extractor tank and held in place by a suitable fitting made out of square mild steel pipes.
The inlet and outlet are appropriately positioned to facilitate uninterrupted flow of the fumes through the extractor; thus ensuring adequate evacuation of the harmful fumes away from the welder and the welding zone. The inlet and outlet ducts (rubber to metal) were precisely dimensioned and fitted to ensure leakproof connection.

The electric motor was connected and fitted with a regulating switch which regulates current through the extraction system.

The fume extractor is a machine that uses an electric motor to power a centrifugal blower. The electric motor provides power for the rotation of the impeller inside the centrifugal blower which leads to suction of fume from a welding process. This fume goes through the capture hood into the machine and an air filter purifies the fume laden air by extracting the welding particles from the fume, and then releases a clean air back to the atmosphere. The fume extractor work on the principle of high volume air, travelling at low velocity. Figure 1 shows the proposed design. 


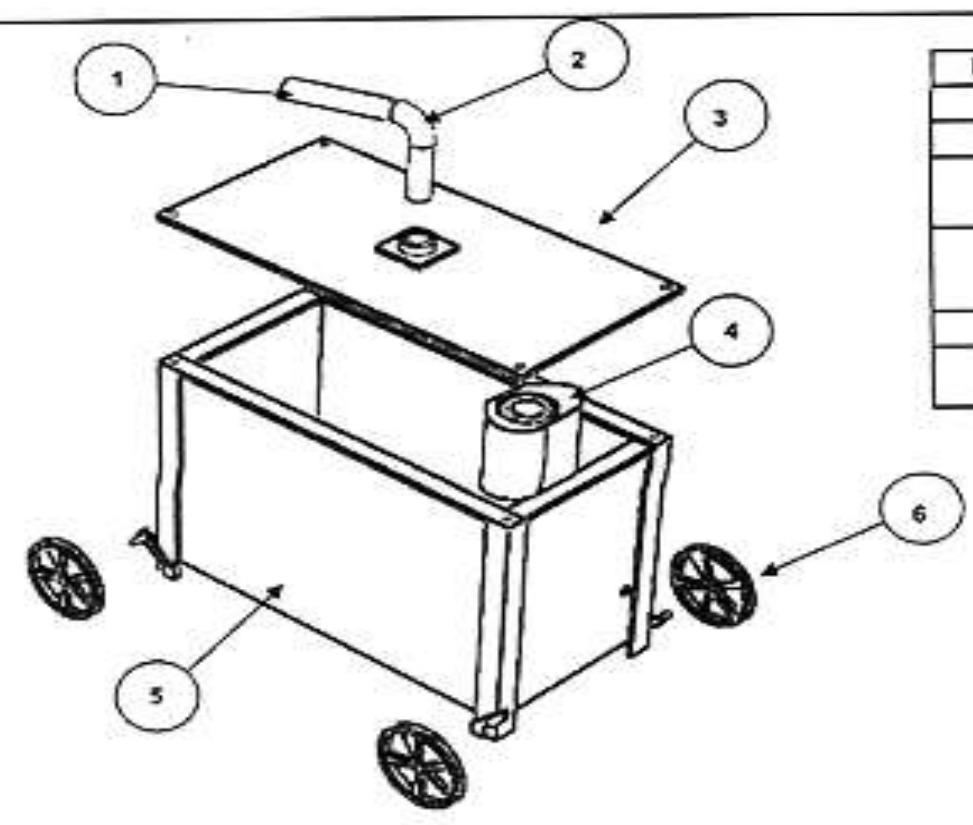

\begin{tabular}{|c|l|c|}
\hline Part No. & \multicolumn{1}{|c|}{ Description } & Qty \\
\hline 1 & Copturing Duct & 1 \\
\hline 2 & Elbow & 1 \\
\hline 3 & $\begin{array}{l}\text { Stainless Steel } \\
\text { Top }\end{array}$ & 1 \\
\hline 4 & $\begin{array}{l}\text { Contrifugal } \\
\text { Blomer }\end{array}$ & 1 \\
\hline 5 & Frame & 1 \\
\hline 6 & Wheels & 4 \\
\hline
\end{tabular}

Figure 1: Isometric drawing of the fume extractor (Assembly of components)

\subsection{Design Calculations}

\subsubsection{Ventilation Rate and Fume Removal}

The ventilation rate required to maintain a concentration of a fume in the occupied zone with the threshold limit value (TLV) can be calculated from equation (1) base on the material balance [6].

$$
Q_{o}=Q_{e x h}+\frac{\left[G\left(10^{6}\right)(1-e)-Q_{e x h}\left(C_{o z}-C_{o}\right)\right]}{K_{c}\left(C_{o z}-C_{o}\right)}
$$

where: $Q_{o}$ is the Air supply rate $(\mathrm{m} / \mathrm{hr}),. Q_{\text {exh }}$ is the Local ventilation exhaust rate $\left(\mathrm{m}^{3} / \mathrm{hr}\right), G$ is the rate of fume generation $(\mathrm{kg} / \mathrm{hr}), n$ is the Local ventilation capacitor efficiency (unit less), $C_{o z}$ is the desired concentration of fumes, gas particulates in occupied zone $\left(\mathrm{mg} / \mathrm{m}^{3}\right), C_{o}$ is the concentration of fumes, gas particulates supply in air $\left(\mathrm{mg} / \mathrm{m}^{3}\right), K_{c}$ is the contaminants removal efficiency (unit less) and $e$ is the coefficient which represents the fraction of time the welder spends at the workstation.

$$
K_{c}=\left(C_{u z}-C_{o}\right) /\left(C_{u z}-C_{o}\right)
$$

where:

$C_{u z}$ is the Concentration of fumes in the upper zone air (if air is evaluated from this zone) or in the exhausted air $\left(\mathrm{mg} / \mathrm{m}^{3}\right)$.

The quantity of fume or gas $\mathrm{G}(\mathrm{kg} / \mathrm{hr}$.) generated in the space can be calculated using one of the following equations [7].

$$
G=R_{1} \times T_{a r}
$$

where:
$R_{1}$ is the fume (gas particles) generation rates, $\mathrm{kg} / \mathrm{min}$ and $T_{a r}=T_{a r}$ is the average arc time per hour for the welding process used ( $\mathrm{min} / \mathrm{hr}$ ).

\subsubsection{Balance Method}

The balance method defines the capture efficiency $(n)$ of the extraction system as the ratio of the mass captured by the extraction ports, $m_{c}$ and the fume mass emitted during the welding process, $m_{e}$ [8]. Equation (4) is used to determine the capture efficiency.

$$
n=\left[\frac{m_{c}}{m_{e}}\right] \times 100 \%
$$

\subsection{Construction of the Fume Extractor}

The construction of the extractor was carried out by deploying basic and appropriate production processes (cutting, welding, drilling, turning, boring, grinding and related processes). The various components were assembled, ensuring proper alignment of all moving parts.

\section{RESULTS AND DISCUSSION}

Design parameters include; volume flow rate of air, torque developed by blower moving air, power required to move air, pressure developed, pressure head $(\mathrm{H})$ developed by the fan, pressure loss in pipe 


\subsection{Design Data}

As obtained from machine design [9], prime mover type is a single phase induction motor, speed of blower $=2300 \mathrm{rpm}$, air duct length $=300 \mathrm{~mm}$, air duct cross section $=35 \mathrm{~mm}$ in diameter, outlet blade diameter $=180 \mathrm{~mm}$, inlet blade diameter $=90 \mathrm{~mm}$, outer blade width $=135 \mathrm{~mm}$, radial blade angle $=$ $90^{\circ}$.

\subsection{Blower Selection for this Design}

After careful considerations of the various types of fans available, the radial-bladed fan was selected as the one suitable for the extractor blower. This fan is characterized by high pressure, medium flow and continuous power increase and very suitable for handling dust-laden, moist air/gases. These fans are equally known to be well suited for high temperatures and can handle heavily contaminated airstreams [10].

Table 2: Results from Impeller analysis

\begin{tabular}{|c|c|}
\hline \multicolumn{2}{|l|}{ Parameters (Units) } \\
\hline $\begin{array}{l}\text { Radial velocity of the inlet impeller } \\
\left(C_{r 1}\right) \mathrm{m} / \mathrm{s} \\
\text { (Flow at inlet is assumed to be non- } \\
\text { directional[6]) }\end{array}$ & 0.000 \\
\hline $\begin{array}{l}\text { Radial velocity of the outlet impeller } \\
\left(C_{r 2}\right) \mathrm{m} / \mathrm{s}\end{array}$ & 10.85 \\
\hline Radius of inlet blade $\left(r_{1}\right) \mathrm{mm}$ & 0.045 \\
\hline Radius of outlet blade $\left(r_{2}\right) \mathrm{mm}$ & 0.090 \\
\hline Impeller tangential velocity $\left(V_{2}\right) \mathrm{m} / \mathrm{s}$ & 21.690 \\
\hline Angular velocity $(\omega) \mathrm{rad} / \mathrm{s}$ & 240.890 \\
\hline Volume flow rate of air $(Q) \mathrm{m}^{3} / \mathrm{s}$ & 0.828 \\
\hline Density of air $(\rho) \mathrm{kg} / \mathrm{m}^{3}$ & 1.200 \\
\hline Mass flow rate $(M) \mathrm{kg} / \mathrm{s}$ & 0.994 \\
\hline Torque $(T) \mathrm{Nm}$ & 1.939 \\
\hline Power required to move air $(P) \mathrm{hp}$ & 0.630 \\
\hline $\begin{array}{l}\text { Mass flow rate of fumes inside the } \\
\text { extractor }(\mathrm{kg})\end{array}$ & 125936079.4 \\
\hline
\end{tabular}

3.3 Analysis of the Centrifugal Blower Impeller Principle of conservation of momentum states that the total momentum of a system in any one direction remains constant unless acted upon by an external force in that direction [9].

At the inlet of impeller, momentum

$$
A I M=M \times W_{1} \times r_{1}
$$

At the exit of impeller, momentum

$$
A E M=M \times W_{2} \times r_{2}
$$

by principle of conservation of momentum [9]; equation (5) is equal to equation (6).

$$
\text { Torque }=\mathrm{Mrv}
$$

where;

$\mathrm{M}$ is the mass of air flowing through $(\mathrm{kg} / \mathrm{s}), r_{1}$ is the Radius of inlet blade $(\mathrm{mm}), r_{2}$ is the Radius of outlet $(\mathrm{mm}), W_{1}$ is the angular velocity of the inlet impeller, $W_{2}$ is the angular velocity of the outlet impeller, $v=$ velocity of the impeller. According to [7],

$$
M=\rho \times Q
$$

where; $M$ is the mass flow rate, $\rho$ is the density and $Q$ is the volume flow rate

$$
T=Q \times \rho \times r \times v
$$

\subsection{Velocity Triangle Positioned at the Impeller Inlet and Outlet}

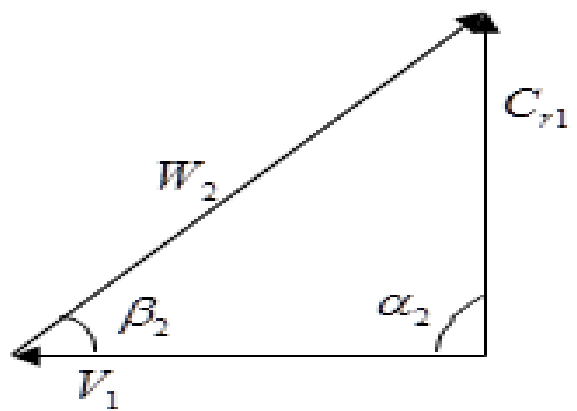

Figure 2: Velocity triangle at inlet blade

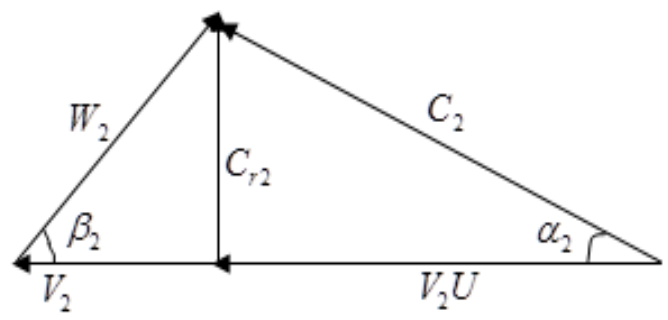

Figure 3: Velocity triangle at outlet blade

where;

$W_{R}$ is the Relative velocity i.e. fluid velocity compared to the rotating impeller, $V$ is the Impeller tangential velocity, $C$ is the Absolute velocity i.e. fluid velocity compared to the surrounding, $C_{T}$ Radial velocity, $\alpha$ is the Relative flow angle, and $\beta$ is the Absolute flow angle

\subsection{Analysis of the Impeller}

Results obtained from the analysis of the impeller are presented in Table 2. 


\section{CONCLUSION}

The construction and testing of the machine has been achieved. The design was done in accordance with standard design specifications and appropriate tests carried out indicated a high level of performance in the extraction of welding fumes. From computations, power requirement is 0.63 horsepower but 1horse power electric motor was selected to provide adequate margin of safety.

The machine is safe and easy to operate and does not require any special technical training on how to operate it. The machine components were coated with aluminum silver spray to make them corrosion resistant. The machine will find extensive use in both local workshops and industries which are involved in welding, soldering, and brazing processes.

\section{REFERENCES}

[1] Mansour A. B. and Mohammad K. G. (2010) Total Fume and Metal Contaminations During Welding in Selected Factories in Jeddah, Saudi Arabia. International Journal of Environmental Research and Public Health, Vol. 7, No 7, pp 2978-2987.

[2] Witt P.J., Solnord C.B.., Mitonni L.J.,Finn S. and Pluta J. , Optimizing the Design of Fume Extraction Hoods Using a Combination of Engineering and CFD Modeling. Applied Mathematical Modeling, Vol. 30, pp. 11671179, 2006.
[3] Kiran K.R., Hamenth K.K.S., Kanteyya A. and Raghavendra D. Design and performance analysis for welding fumes extraction system. International Journal of Emerging Trends in Science and Technology Vol. 2, No. 8, pp: 3060-3063. 2015.

[4] Lehnert M., Pesch B., Lontz A., Pelzer J., Kendzia B., Gawrych K., Heinze E. and VanGeler R. . Exposure to inhalable, respirable, and ultrafine particles in welding fumes. Annals of Occupational Hygiene Vol. 56 (5), pp: 557 567. 2012.

[5] Ibhadode, A. O. Introduction to Manufacturing Technology, Ambik Press, Benin City, Edo State, Nigeria. 2001

[6] McDermott, H. J. Handbook of Ventilation for Contaminant Control $2^{\text {nd }}$ Edition. 1985.

[7] Francis B. Factors Affecting the Capture Efficiency of a Fume Extraction Torch for Gas Metal Arc Welding. Annals of Occupational Hygiene, Vol. 60, No. 6, pp: 761 - 770, 2016.

[8] Caster, H.R. Gas Metal Arc Welding Fume Generation Using Pulse Current Welding. Welding Journal Vol. 74, No. 2, pp. 59 - 68. 1995.

[9] Khurmi, R. S. and Gupta, J. K. Machine Design, Chand and Company Itd, New Dehli. 2006.

[10] Shan-jun M.O., Zhao Z., Liang D. and Zhi-jian $\mathrm{H}$. Engineering Simulation of Smoke Extraction Design in Atrium Fires of Student Union, Procedia Engineering Vol. 11, pp: 325-334. 2011. 